\title{
Comprando e vendendo Alcorões no Rio de Janeiro do século XIX
}

\author{
A LBERTO DA COSTA E SI LVA
}

$\mathrm{N}$ O DIA 22 de setembro de 1869, o conde de G obineau, na época ministro da França no Brasil, escreveu num relatório político para o Q uai d'O rsay ${ }^{1}$ que os livreiros franceses Fauchon e D upont costumavam vender todos os anos, em sua loja no Rio de J aneiro, quase cem exemplares do Alcorão. Embora muito caro (entre 36 e 50 francos franceses), o livro era comprado quase que exclusivamente por escravos e ex-escravos, que tinham de fazer grandes sacrifícios para adquiri-lo. Alguns deles compravam o livro a prestação, e levavam um ano para pagá-lo. Como os Alcorões eram escritos em árabe - e a mão, pois, naquela época, não eram ainda impressos (e para este fato me chamou a atenção J ohn $\mathrm{O}$. H unwick -, Fauchon e D upont importavam também gramáticas daquele idioma, com explicações em francês, pois os escravos e ex-escravos desejavam aprender o árabe, a fim de ler e compreender o livro sagrado no original.

$Q$ uase certamente, a livraria tinha Gobineau como um bom freguês. $E$ um freguês especial. Representante diplomático da França, era também um ficcionista muito conhecido e o autor de uma obra polêmica, o famoso Essai sur l'inégali té des races humaines. $\mathrm{N}$ a loja de Fauchon e D upont, ele provavelmente obtinha a maioria dos últimos lançamentos franceses. D evia passar por lá todas as semanas, de modo que os dois livreiros pronto perderam o receio de falar-lhe sobre a venda de livros (em especial de livros proibidos) aos escravos. Gobineau recebeu a informação da melhor das fontes, portanto, e não tinha motivo para inflar o número de exemplares do Alcorão que eram vendidos no Rio de Janeiro: cem cópias e todas elas em árabe. Ainda que, para não sair de seus hábitos, Gobineau exagerasse, e Fauchon e D upont não vendessem mais do que a metade, cinqüenta Alcorões já era uma boa quantidade, a indicar, primeiro, que o número de islamitas africanos ou descendentes de africanos na capital do I mpério era, naquela época, muito maior do que as aparências poderiam sugerir e, segundo, que eram islamitas estritos, pois não aceitavam o livro sagrado em nenhuma outra língua exceto aquela em que o recebeu $\mathrm{M}$ aomé.

Talvez muitos dos compradores do Alcorão não fossem capazes de o ler, mas queriam possuí-lo como o repositório da palavra de $D$ eus, como um objeto de prestígio, como uma fonte de poder sobrenatural ou como um símbolo mate- 
rial da fé. De acordo com dois agudos observadores - $N$ ina Rodrigues, no final do século XIX, em Salvador, e J oão do Rio, nos primeiros anos do século XX, no Rio de Janeiro -, a primeira coisa que chamava a atenção de quem visitasse a residência de um islamita eram os livros religiosos dispostos sobre a mesa². A maioria dos muçulmis, muxurumins ou malês (como os negros muçulmanos eram conhecidos pelo povo dos orixás, pelos adeptos da umbanda e pelos católicos) podia ler o Alcorão ou desejava ser capaz de o ler. O s livros de gramática importados por Fauchon e Dupont deviam ter por principais compradores a gente jovem que se estava educando nas doutrinas e nos ritos da fé.

J oão do Rio era um excelente repórter, mas não tinha o menor respeito ou apreço pelas práticas religiosas dos africanos e de seus descendentes, nem por qualquer outra religião; era irônico e crítico em relação a todas elas. Essa circunstância dá ao que escreveu so bre o islamismo no Rio de J aneiro um toque especial de autenticidade. $\mathrm{N}$ ão duvido, por isso, de suas palavras, quando nos conta que os rapazolas tinham de estudar com afinco, se queriam tornar-se clérigos ou alufás, e que na cidade havia pessoas capazes de ensinar-lhes o Alcorão e de examiná-los sobre o que tinham aprendido. U m de seus informantes afirmaraIhe que o candidato aprovado era conduzido em triunfo, a cavalo, pelas ruas de um subúrbio distante, acompanhado pelos fiéis.

João do Rio confirma, a respeito dos maometanos no Rio, o que N ina Rodrigues escrevera sobre os maometanos na Bahia: que formavam uma comunidade quase fechada. $\mathrm{N}$ ina R odrigues errou, porém, ao reagir com incredulidade ao que o imame de Salvador e vários outros moslins Ihe haviam dito: que, no Rio, os muçulmis estavam igualmente bem organizados, possuíam uma mesquita e realizavam publicamente, sem disfarce, algumas festividades e cerimônias. $M$ ais tarde, ele obteve a informação suplementar de que a mesquita à qual os negros tinham acesso era mantida pela comunidade árabe. Esta última informação, so bre ser a mesquita pública mantida pelos árabes, é que estava equivocada. A té o final do século XIX, o número de imigrantes do I mpério $O$ tomano recebido pelo Brasil foi insignificante: somente 3.023, de 1846 a $1889^{3}$, e quase todos cristãos sírios e libaneses que fugiam das perseguições turcas.

Roger Bastide também se mostrou incrédulo em relação à existência de uma mesquita no Rio de Janeiro e de uma outra em São Paulo ${ }^{4}$. Com certeza não havia um edifício público dedicado ao islame. O s machacalis (da palavra hauçá masallachi ?) ficavam provavelmente nas residências dos imames ou de alguns alufás. No Rio do início do século XX, o principal machacali situava-se na rua Barão de São Félix, na casa do imame. N em poderia ser de outro modo na segunda metade do oitocentos, pois as leis do I mpério do Brasil (especialmente o Código Penal de 1830) proibiam os ritos de todas as religiões, exceto a católica, em qualquer "edifício que tivesse alguma forma exterior de templo". Foi só em 1870, para atender ao pedido dos imigrantes al emães, que os cultos protestantes foram aceitos como legais pelo Estado. A té essa data, não havia templos públicos 
protestantes no Brasil, nem uma só sinagoga que se mostrasse como tal, embora seus cultos fossem tolerados, sempre que de portas fechadas. Portanto, aquilo a que os informantes de $\mathrm{N}$ ina Rodrigues estavam aludindo como sendo uma mesquita era, provavelmente, a morada do imame, onde os fiéis se reuniam às sextasfeiras, para orar juntos. M as era, sem dúvida alguma, uma mesquita, uma casa de oração, um espaço dedicado ao fervor religioso, similar a um machacali da Salvador de N ina Rodrigues: a casa do lemano Luís, no no 3 da rua Alegria 5 .

Gobineau é claro: como não se aceitava, no Império do Brasil, a prática do islamismo, os moslins tentavam ocultar sua fé verdadeira e simulavam ser cristãos. Q uando se perguntava por seus correligionários a quem se sabia ser muçulmano, a resposta era, quase sempre, a de que não passavam de uns pou$\cos$, de uma minoria insignificante, e que se contavam pelos dedos das mãos. M esmo depois da Abolição e da Proclamação da República, continuaram os maometanos a insistir em que não possuíam expressão numérica importante, bem como em manter discrição sobre sua crença. $E$ tinham um passado de razões para isso.

U ma pesquisa nos arquivos da polícia do Rio de J aneiro, São Luís, Recife, Salvador e outras cidades brasileiras trará à luz dados importantes sobre o tipo de perseguições que so freram, durante o I mpério, as pesso as suspeitas de islamismo. A pesquisa também revelará a completa ignorância dos funcionários policiais sobre o islame. $\mathrm{N}$ a opinião deles, os moslins, além de serem difíceis e irritantes de lidar, formavam uma facção insubmissa e perigosa, sempre propensa a antago nizar as autoridades e a rebelar-se.

Algumas das ações repressivas contra os muçulmanos repercutiam na imprensa, embora raramente, porque os vexames contra escravos ou ex-escravos eram matéria de rotina. N os jornais do século XIX, podemos encontrar, porém, aqui e ali, bons exemplos das suspeitas e perseguições que recaíam sobre os islamitas. Assim, na edição de 21 de setembro de 1853 do diário fluminense Correio M ercantil, na qual se publicou um artigo da autoria de um correspondente em Pernambuco ${ }^{6}$, com a seguinte história. No começo do mês, a polícia do Recife prendera um grupo de africanos que, sob a liderança de um alufá nagô, um certo R ufino, chamado Abuncare em sua terra natal, estava formando "uma nova seita religiosa". Com Abuncare foi encontrado "um livro, que ele declarou" - escreve incredulamente o jornalista - ser "o Alcorão", bem como "muitas folhas de papel escritas em hebraico" (sic). A polícia contou-Ihe que Abuncare, um liberto, era muçulmano dos mais fanáticos, e de uma tal maneira, que, quando alguém contestava suas crenças, reagia com violência. 0 correspondente acrescentava que Abuncare merecia a prisão, porque era um vadio e "explorava" seus correligionários, "obrigados" a arcar com sua manutenção. E assim concluía: por causa desse adepto de M aomé, Recife passou vários dias em estado de alarme, pois muita gente acreditava que uma rebelião de escravos estava sendo preparada pelos muçulmanos. 
$\mathrm{N}$ a correspondência da semana seguinte, o mesmo jornalista nos informa de que Abuncare recuperara a liberdade, uma vez que as autoridades judiciárias nada haviam encontrado nas suas atividades religiosas que pudesse significar perigo para a ordem pública. 0 jornalista reagiu com indignação, sugerindo que A buncare fosse imediatamente mandado de volta à África, a fim de impedir-se que continuasse a contaminar outros escravos e libertos com suas nocivas idéias religiosas ${ }^{7}$.

Início da Surata da Vaca do Alcorão, em árabe

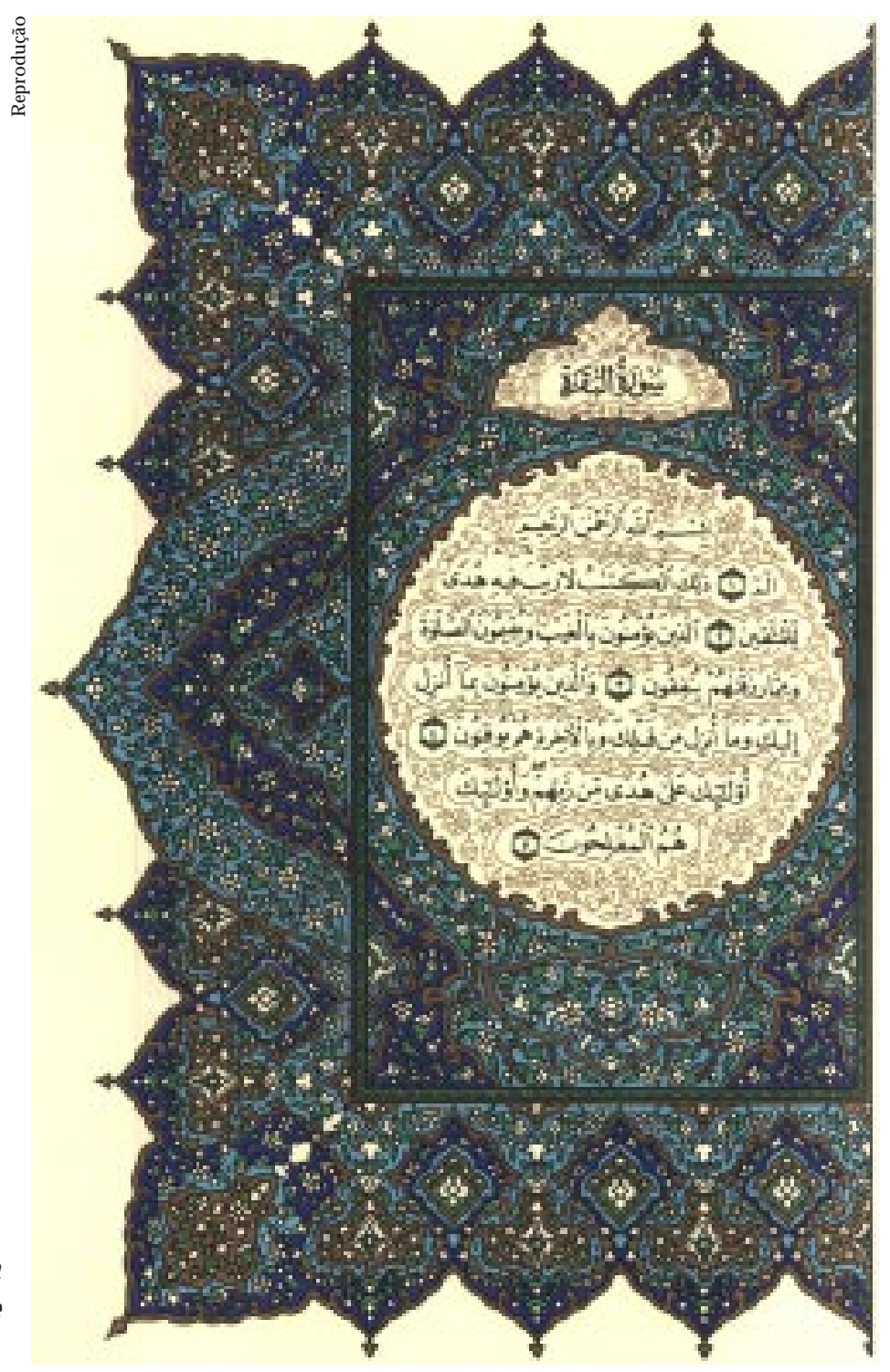

Roger Bastide, assim como, antes dele, Arthur Ramos ${ }^{8}$, tinha dúvidas sobre 0 islamismo dos chamados muçulmis. Ambos opinavam não serem esses negros verdadeiros muçulmanos, porém tão-somente adeptos de uma espécie de sincretismo do islame com crenças e práticas pagãs, um sincretismo que tinham trazido consigo da África. É curioso observar como esses dois autores, que sempre olha- 
ram com benevolência para o catolicismo popular, se mostram severos no julgamento sobre o que deveria ser um verdadeiro muçulmano. E é mais interessante ainda verificar que apresentam como provas de sincretismo práticas reguladas ou aceitas por ramos do islame, como a feitura de grigris, as pequeninas bolsas de couro contendo versículos do Alcorão, a salat al-istisqa' ou oração pela chuva, a crença nos jinns e as tabuinhas de escrever ou atôs (de allo, em hauçá?), com versículos do Alcorão que se lavavam, sendo a água, em seguida, bebida pelos fiéis.

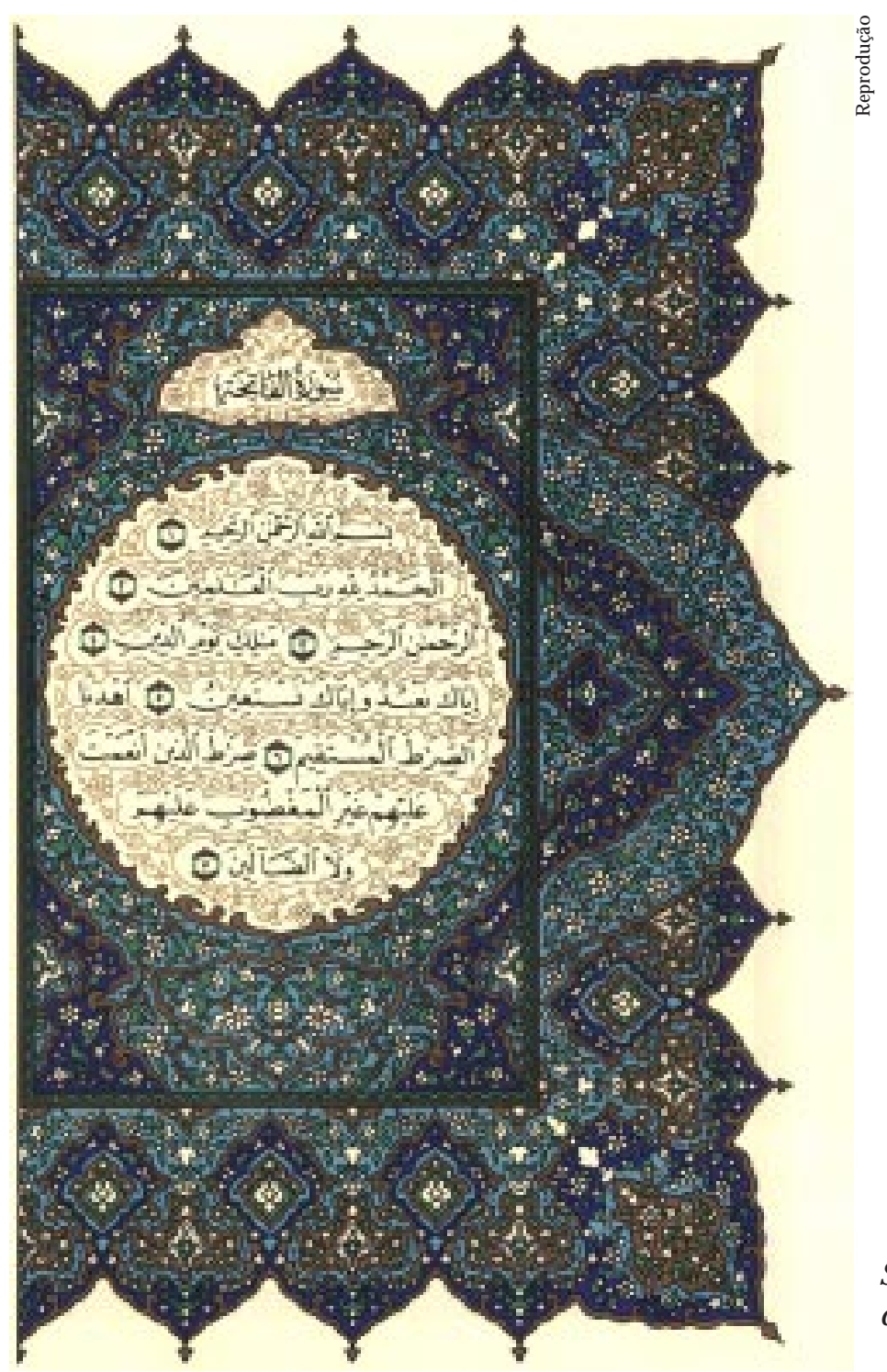

Surata de A bertura do Alcorão, em árabe

J oão do Rio não era antropólogo nem sociólogo. Tampouco estava obcecado, como tantos eruditos, no Brasil e em Cuba, com os problemas da aculturação, da contra-aculturação e do sincretismo. Escreveu sobre o que viu e o que lhe contaram. Seus moslins, assim como os de M anuel Q uerino e N ina Rodrigues, tentavam, num ambiente hostil, cumprir seus deveres religiosos com devoção e rigor. É 
verdade que, depois da Abolição e da República, cessou, pelo menos no Rio de J aneiro, a perseguição aos muçulmanos. A polícia do Rio tratava-os com mais consideração do que aos devotos da umbanda e do candomblé ${ }^{9}$, cujo ruidoso toque de tambores provocava muitas vezes reações negativas e protestos dos vizinhos.

$\mathrm{N}$ a capital da República, de acordo com J oão do Rio, os moslins africanos possuíam um imame ou lemano (que morava na rua Barão de São Félix), cádis ou ali kalis (outra palavra hauçá, alkali), juízes subtitutos e oficiantes que dirigiam as preces coletivas e cerimônias. Praticavam a circuncisão (kola), jejuavam no Ramadã e mantinham mais de uma esposa. Eram estritos no rezar as orações diárias (ki ssium) e no cumprir as abluções rituais, al gumas vezes vestidos deabadá, a túnica branca, com um gorro vermelho, o filá, na cabeça. À noite, não largavam o rosário (tessubá) das mãos. João do Rio não menciona que matassem carneiros no Id al-A dha e no Id al-Fitr, mas provavelmente o faziam, como aparecem registros em $\mathrm{N}$ ina R odrigues ${ }^{10}$ e $\mathrm{M}$ anuel Q uerino ${ }^{11}$, na Bahia. Realizavam também, ainda que discretamente, al guma catequese, pois, como nos informa N ina R odrigues ${ }^{12}$, a mulher do lemano de Salvador nascera no Brasil e convertera-se ao islamismo no Rio de J aneiro, onde morara durante al gum tempo.

Em seu relatório, Gobineau escreve que todos os africanos moslins eram minas, denominação que no Rio de Janeiro e outras regiões do sul do Brasil significava qualquer africano que não fosse banto ou qualquer um que tivesse embarcado entre a costa do Senegal e os Camarões. Ele também menciona que um bom número dos africanos muçulmanos de Salvador, aos se tornarem livres, regressavam à Africa, mas que outros preferiam emigrar para o Rio de Janeiro. Q uarenta anos mais tarde, João do Rio confirmaria a informação de Gobineau: muitos dos moslins do Rio de Janeiro provinham da Bahia. É possível que quisessem não apenas ficar longe de seus antigos donos, mas também escapar de constrangimentos pessoais, da desconfiança e das perseguições que se seguiram às revoltas das primeiras quatro décadas do século XIX.

Ao chegar ao Rio, esses baianosjá encontraram muitosminas, desembarcados pelos navios negreiros diretamente da costa africana. E outros, trazidos do N ordeste, para serem vendidos no Rio de Janeiro e em São Paulo, durante 0 auge do café. E sse comércio inter-regional começou por volta de 1830, aumentou depois de 1850 e atingiu suas cifras mais elevadas nos anos de $1870^{13}$. Em conseqüência dessa migração forçada, uma área de predomínio banto como a província do Rio de Janeiro presenciou, durante cinco décadas, o crescimento numérico dos chamados minas: não somente iorubás, mas também fons, hauçás, gãs, guns, evés, baribas, fantes, bornus, nupes, grunces, mahis e mandingas. Alguns deles eram muçulmanos.

Antes mesmo da Abolição, os cativos e libertos que chegavam do norte ao Rio de Janeiro começaram a formar comunidades conforme a terra de origem, não na África, mas no Brasil. O s da Bahia, sobretudo os iorubás ou nagôs, mas também os outros, procuravam instalar-se num mesmo bairro, em volta ou perto 
da casa de um homem ou de uma mulher de prestígio - de uma ialorixá, de um babalorixá ou de alguém que tivesse chegado antes e fosse considerado como bem-sucedido, social ou economicamente. $N$ a virada para o século $X X$, um grande número de famílias da Bahia morava num pedaço do Rio de Janeiro, junto à Praça 11, chamado Pequena África. N essa Pequena África, os moslins concentraram-se em algumas poucas ruas: São D iogo, Barão de São Félix, do H ospício, do $\mathrm{N}$ úncio e da América ${ }^{14}$.

Buscavam os muçulmanos viver reunidos nos mesmos logradouros. M as o que decidia o local onde se fixava uma família não era ser crente nos orixás, nem muçulmano, católico, iorubá, jeje ou hauçá, porém, sim, ter vindo de Salvador, fazer parte daquilo que podemos definir como diáspora baiana. Foi a partir dessa nova identidade que novas teias de solidariedade se teceram. Era por intermédio de Salvador que se importavam de L agos ou de Ajudá nozes-de-cola, cauris, azeite-de-dendê, sabão e pano-da-costa. Passou-se, assim, no Rio de Janeiro, algo muito semelhante ao que acontecera com os africanos que retornaram do Brasil à África, e formaram em Acra, Anexô, Ajudá, Badagry, Porto N ovo e Lagos os seus bairros próprios, e desenvolveram uma nova identidade grupal, a de "brasileiros" .

O s negros islamitas nunca foram tão numerosos no Rio quanto em Salvador, onde, de acordo com $\mathrm{N}$ ina Rodrigues, um em cada três dos velhos africanos, antes da insurreição de 1835, era maometano ${ }^{15}$. $\mathrm{N}$ a época de Gobineau, 0 islame contava, porém, com um volume de adeptos suficiente para adquirir algumas dezenas de exemplares do Alcorão por ano e tornar o livro sagrado o bestseller da livraria de Fauchon e D upont. Três décadas e meia mais tarde, já não havia mercado para novos Alcorões no Rio de Janeiro. Quando João do Rio escreveu seus artigos de jornal sobre as religiões da capital da República, o número de moslins havia diminuído consideravelmente. Talvez parte da informação que compilou já pertencesse ao passado. A um passado recente, mas passado. Foi ele contemporâneo de alguns moslins que se tornaram figuras lendárias na história do Rio de J aneiro - entre os quais o morador de um prédio de dois andares, o 191, na Praça 11, Assumano M ina do Brasil, famoso não só como alufá, mas também por ser um homem belíssimo -, porém a antiga comunidade muçulmana já começava a desaparecer.

M uitos de seus membros foram mandados de volta para a Costa africana pelas autoridades brasileiras, outros retornaram à África por vontade e iniciativa próprias, por não aceitarem continuar a ser governados por infiéis, ou descontentes com as restrições que seus cultos sofriam no Brasil, ou insatisfeitos com a desconfiança, misturada a uma espécie de medo e respeito, que os muçulmis inspiravam aos outros negros. A maioria morreu. Alguns deles, já na velhice, experimentaram a desilusão de ver filhos e netos abandonarem, pouco a pouco, o islamismo e se juntarem a outros grupos religiosos. Tal como aconteceu em Salvador, onde alguns velhos moslins se queixaram a $\mathrm{N}$ ina Rodrigues de que seus descendentes estavam trocando o islame pelos cultos dos orixás e pelo catolicismo ${ }^{16}$. 


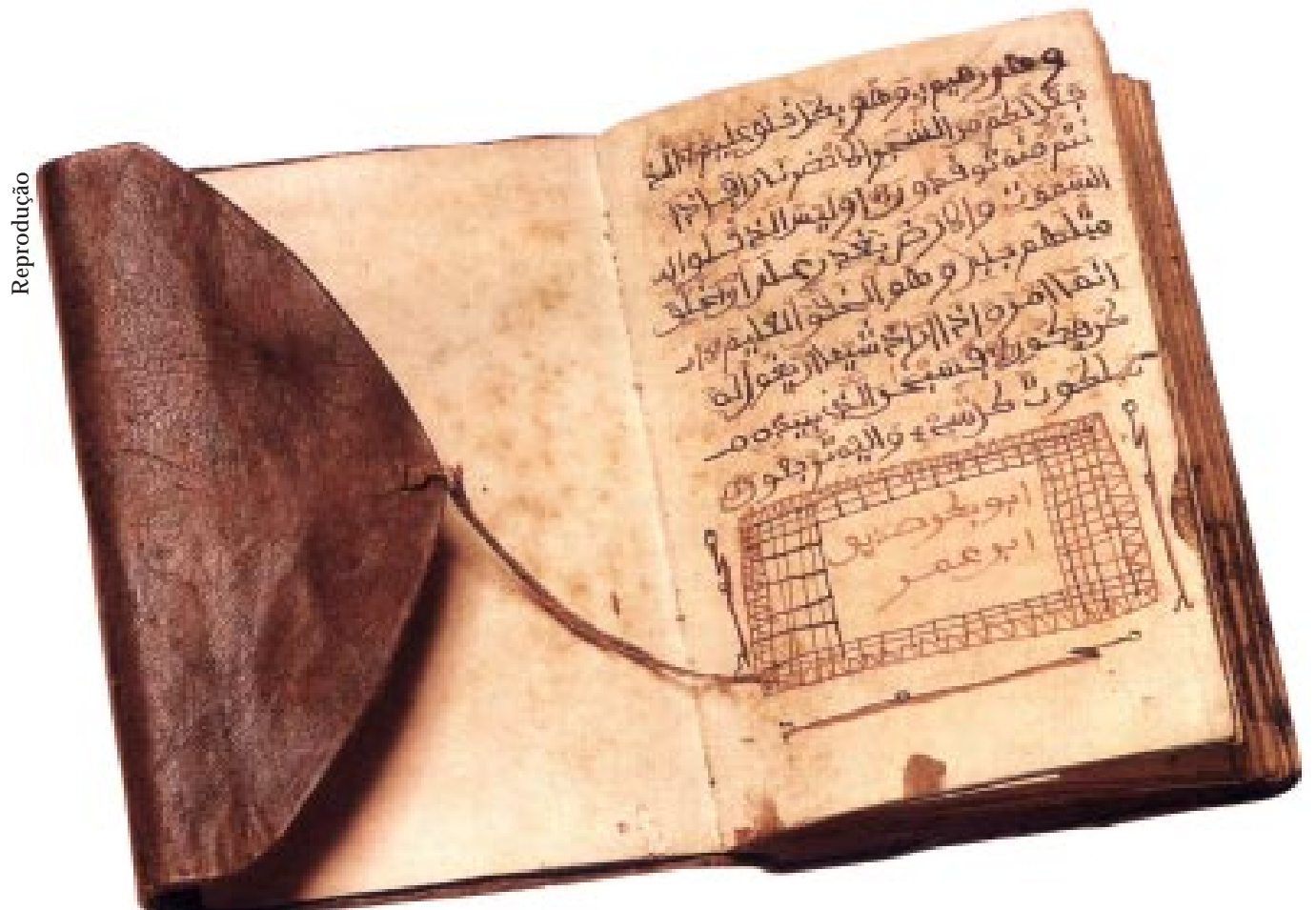

Livrinho encontrado preso ao pescoço de um negro mor to durante a insurreição dos M alês, na Bahia, em 1835.

Com o término, no início do século $X X$, das conexões marítimas diretas entre Salvador e L agos, os islamitas que viviam no Brasil perderam inteiramente 0 contato com seus correligionários na África. Tornaram-se cada vez mais isoladose herméticos, a ressentir-se da rejeição dos demais negros e obrigados, para serem aceitos, a fingir o que não eram e a adotar al guns dos comportamentos dos infiéis.

No Rio, como na Bahia e noutros lugares do Brasil, os muçulmis desprezavam a religião dos orixás e seus seguidores, e os adeptos dos orixás zombavam das práticas religiosas dos moslins. Embora os islamitas fossem geralmente respeitados como pessoas sérias e virtuosas, eram também temidos pelo segredo que os cercava. N ão obstante, faziam parte, no Rio, da mesma diáspora, viviam entre os baianos de outras denominações religiosas e era no meio deles que escoIhiam mulheres e maridos. Q uase desde o princípio, os moslins menos estritos se misturaram e fraternizaram com os baianos de outras religiões: iam às suas festas, inclusive aos bailes e às rodas de samba, embora nunca tomassem bebidas alcoólicas nem comessem feijoada, porque continha carne de porco. Seus filhos e fiIhas viam-se, entretanto, obrigados a escolher entre ser parte de uma minoria sob suspeita ou aderir aos valores comuns do grupo dentro do qual viviam. Por isso, alguns dos que tinham sido criados como moslins acabaram por converter-se à religião dos orixás, à umbanda, ao catolicismo, ao evangelismo ou ao espiritismo.

A senhora Carmen Teixeira da Conceição serve de exemplo. Nascida em 1877, ela foi para o Rio de J aneiro em 1893, onde continuou a praticar a religião 
muçulmana. Já adulta, tornou-se cristã. Talvez se tenha sentido sem forças para seguir o islame em solidão e segredo. Talvez necessitasse de companhia na fé. M onoteísta, juntou-se aos que eram como ela, ainda que lessem um outro L ivro. Morreu como católica devota, e das mais devotas, pois era membro de cinco confrarias religiosas e, por mais de cinqüenta anos, assistiu, to dos os domingos, a duas missas. A pesar disso, numa conversa de fim de vida, os seus ol hos marejaramse de lágrimas, ao recordar a sua crença de menina e moça e os velhos muçulmanos do Rio de Janeiro ${ }^{17}$.

\section{N otas}

1 Jean-François de Raymond (ed.), A rthur de Gobineau et le Brésil: correspondance diplomatiquedu M inistredeFranceà $\mathrm{R}$ io deJ aneiro, G renoble, Presses U niversitaires de Grenoble, 1990, pp. 143-148.

$2 \mathrm{~N}$ ina Rodrigues, OsafricanosnoBrasil, ed. revista e prefaciada por H omero Pires, São Paulo, Companhia E ditora N acional (Brasiliana), 1932, p. 96; J oão do R io, A sreligiões no R io, Rio de Janeiro, N ova Aguilar, 1976 (1 1 ed. 1902), p. 23.

3 J. Fernando Carneiro, I migração e colonização no Brasil, Rio de J aneiro, Faculdade N acional de Filosofia da U niversidade do Brasil, 1950, mapa defronte à p. 60.

4 Roger Bastide, A sreligiões africanas no Brasil, Trad. M aria Eloisa C apellato e O lívia Krähenbühl, São Paulo, Livraria Pioneira/ Edusp, 1971, vol. 1, p. 205.

$5 \mathrm{~N}$ ina Rodrigues, op. cit., p. 95.

$6 \mathrm{M}$ anolo Florentino chamou-me a atenção sobre esta matéria publicada pelo Correio Mercantil.

7 Correio M ercantil, Rio de Janeiro, 28 de outubro de 1853.

8 Arthur Ramos, 0 negro brasileiro, Recife, Fundação Joaquim N abuco/ M assangana, 1988 (1 1 a ed. 1934), pp. 66-72; A sculturasnegras do novo mundo, São Paulo, Companhia Editora N acional, 1946 (1 a ed. 1936), pp. 314-329; I ntrodução à antropologia brasileira, Rio de J aneiro, C asa do Estudante do Brasil, 1943, vol. I, pp. 410-432.

9 Conforme disse d. Carmem Teixeira da Conceição, que tinha 105 anos de idade quando falou com J oão Baptista M . Vargens e N ei Lopes, I Samismo enegritude, Rio de J aneiro, Setor de Estudos Árabes da Faculdade de L etras da U niversidade Federal do Rio de Janeiro, 1982, p. 76.

$10 \mathrm{~N}$ ina Rodrigues, op. cit., p. 92.

11 M anuel Querino, Costumes africanos no Brasil, 2a ed., Recife: Fundação J oaquim N abuco/ M assangana, 1988, p. 71 (este texto foi publicado pela primeira vez em 1916).

$12 \mathrm{~N}$ ina Rodrigues, op. cit., p. 95.

13 Evaldo Cabral de M ello, 0 nor teagrário eo I mpério, Rio de Janeiro, N ova Fronteira, 1984, pp. 28 e 39.

14 Roberto M oura, Tia Ciata ea Pequena Á frica no Rio de Janeiro, 2aㅡ ed., Rio de Janeiro, Prefeitura da Cidade do Rio de Janeiro/ D epartamento Geral de D ocumentação e Informação Cultural, 1955, p. 133. 
$15 \mathrm{~N}$ ina Rodrigues, op. cit., p. 94.

16 I dem, p. 96.

17 J oão Baptista M. Vargens e N ei Lopes, op. cit., pp. 75-76.

R ESU Mo - NA SEGUNDA metade do século XIX, uma livraria francesa vendia aos negros do Rio de Janeiro um bom número de exemplares do Alcorão. H avia na capital do I mpério uma comunidade muçulmana, formada em parte por ex-escravos imigrados da Bahia. $\mathrm{N}$ o início do século XX, essa comunidade ainda era ativa e mantinha até mesmo escola corânica. Com o término dos contactos diretos entre o Brasil e a África, os islamitas do $\mathrm{R}$ io tornaram-se cada vez mais isolados e os seus descendentes acabaram por se converter a outras crenças.

A BSTRACT - IN THE latter half of the $19^{\text {th }}$ century, a French bookstore in Rio de J aneiro sold a large number of copies of the Koran to the city's blacks. The capital of the Empire boasted a M uslim community, partly comprised of former slaves who had migrated from Bahia, and which was still active in the early $20^{\text {th }}$ century, to the point of maintaining a Koranic school. However, with the end of direct contact between Brazil and Africa, Rio's islamites became increasingly isolated and their descendants eventually converted to other beliefs.

A l berto da Costa eSilva, diplomata e escritor, é autor, entre outras obras, de A enxada ea lança: a África antes dos portugueses (1992), A manilha eolibambo. A Á frica ea es cravidão de1500 a 1700 (2002). Presidente da A cademia B rasileira de L etras (2002-2003).

Este texto foi publicado no livro do autor U m rio chamado A tlântico. A África no Brasil eo Brasil na Á frica, Rio de J aneiro, N ova Fronteira/ Editora da U FRJ , 2003, pp. 177-186.

Texto recebido e aceito para publicação em 5 de dezembro de 2003. 